\title{
Helicobacter pylori Genotype and Polymorphisms in DNA Repair Enzymes: Where Do They Correlate in Gastric Cancer?
}

\author{
ISABELLE JOYCE DE LIMA SILVA-FERNANDES, MD, ${ }^{1 *}$ THAYSE AZEVEDO DA SILVA, $\mathrm{MD}^{2}{ }^{2}$ \\ LUCYMARA FASSARELLA AGNEZ-LIMA, PhD, ${ }^{2}$ MÁRCIA VALÉRIA PITOMBEIRA FERREIRA, PhD, ${ }^{1}$ AND \\ SILVIA HELENA BAREM RABENHORST, PhD ${ }^{1}$ \\ ${ }^{1}$ Departamento de Patologia e Medicina Legal, Universidade Federal do Ceará, Fortaleza, Brazil \\ ${ }^{2}$ Departamento de Biologia Celular e Genética, Universidade Federal do Rio Grande do Norte, Natal, Brazil
}

\begin{abstract}
Background and Objectives: One of the mechanisms proposed by which H. pylori causes gastric cancer (GC) is through DNA damage due to chronic inflammation. Genomic integrity is guaranteed by repair enzymes such as APE-1, OGG-1, and PARP-1. Host genetic polymorphisms associated with the bacterial strain may influence the ability to repair the damage, contributing to the development of H. pylori-associated GC. The aim of this study was to determine the association of the polymorphisms APE-1 (T2197G), OGG-1 (C1245G), and PARP-1 (A40676G) with H. pylori-genotype in 109 patients with GC.

Methods: Polymorphism was assessed by polymerase chain reaction (PCR)-restriction fragment length polymorphism (RFLP) and $H$. pylori detection/genotyping by PCR.

Results: In the intestinal subtype, $P A R P-1$ wild-type was more frequent $(P=0.001)$ in patients $>50$ years old. The repair enzymes genotypes analyzed in combination showed that the less pathogenic strains are associated with the $A P E-1$ polymorphic allele and, unexpectedly, with $P A R P-1$ wild-type, but this last one associated with $A P E-1$ polymorphic allele or in older patients.

Conclusions: Our results indicate the importance of $H$. pylori and APE-1 genotypes in the gastric carcinogenesis. Also, support the hypothesis of a decrease of PARP-1 wild-type activity in older individuals. Taken together these data may be an important clue to understand the role of low-virulence strains of $H$. pylori in gastric carcinogenesis and point the importance to analyze the polymorphisms as a group.
\end{abstract} J. Surg. Oncol. 2012;106:448-455. (C) 2012 Wiley Periodicals, Inc.

KEY WoRDS: APE-1; PARP-1; OGG-1; gastric cancer; H. pylori; polymorphisms

\section{INTRODUCTION}

Gastric cancer (GC) is the fifth most common cancer and the second leading cause of cancer-related mortality in the world [1]. In Brazil it is a relevant cause of cancer-related death patients, with high prevalence in the Northeast region [2]. Adenocarcinomas represent $90-95 \%$ of gastric tumors [3], divided into intestinal and diffuse subtypes, according to the Lauren classification, with distinct histological and epidemiological features, as well as different prognosis [4,5].

Gastric carcinogenesis is a multifactorial process, and Helicobacter pylori (H. pylori) is the main initiator of inflammation and atrophic changes in the gastric mucosa [6]. The association between chronic H. pylori infection and the development of GC is well established [7]. Although it is known that both bacterial virulence and host genetic susceptibility are associated with cancer risk and progression [8], the exact host and bacterial genotypes relevant to this relationship are still unknown.

H. pylori has a great genetic diversity, and virulence factors play important roles in mucosal injury, especially cagA (cytotoxin associated gene $A$ ) and vacA (vacuolating cytotoxin A) genes. cag A is involved in many cellular host alterations and tightly associated with GC risk [9,10]. vacA gene is present in essentially all $H$. pylori strains. It is a potent toxin and induces the formation of vacuoles in host cells. There are two types of signal region (s1 and s2) and middle region ( $\mathrm{m} 1$ and $\mathrm{m} 2$ ) in this gene. The mosaic combination of these exhibit different levels of toxin activity and are associated with different risks of gastrointestinal diseases. In general, vacAs $1 \mathrm{~m} 1$ produces a large amount of toxin and induces a higher vacuolating activity, whereas vacAs $2 m 2$ produces little or no toxin [11].
Additionally, cagE and virb 11 genes were found at a relevant frequency in the GC patients [12]. cagE has been associated with induction of IL-8 in gastric epithelial cells, enhancing the inflammation [11,13]. ATPase virB11 protein is one of the bacterial type IV secretion system, essential for transport of bacterial components $[14,15]$.

On the other hand, the persistent inflammatory process due to $H$. pylori infection generates large amounts of reactive oxygen species (ROS), which can cause high DNA oxidative damage levels $[16,17]$ and, therefore, requires continuous repair. The base excision repair pathway (BER) is the most important mechanism in the repair of oxidative damage DNA $[18,19]$.

One abundant type of DNA damage resulting from ROS exposure produces oxidized bases such as guanine (8-OHdG), which has been shown to be highly mutagenic, resulting in $\mathrm{G}: \mathrm{C}$ to $\mathrm{T}$ :A transversion [20]. The major excision repair enzyme for $8-\mathrm{OHdG}$ is 8-oxoguanine DNA glycosylase 1 (OGG-1). Apurinic/apyrimidinic (AP) sites generated by the removal of oxidized bases are repaired by APE- 1 , a

Grant sponsor: Ministério da Ciência e Tecnologia/Conselho Nacional de Desenvolvimento Científico e Tecnológico (MCT/CNPq); Grant number: 480554/2008 0; Grant sponsor: Coordenação de Aperfeiçoamento de Pessoal de Nível Superior (CAPES).

*Correspondence to: Isabelle Joyce de Lima Silva-Fernandes, MD, Departamento de Patologia e Medicina Legal, Universidade Federal do Ceará, Fortaleza, Brazil. Fax: +55-85-32673840.

E-mail: isabellejoyce@gmail.com

Received 27 July 2011; Accepted 6 February 2012

DOI 10.1002/jso.23077

Published online 28 February 2012 in Wiley Online Library (wileyonlinelibrary.com). 
multifunctional protein that plays a central role in the BER pathway. It cleaves $5^{\prime}$ of DNA abasic sugar residues and acts as a $3^{\prime}$ phosphoesterase to initiate the repair of strand breaks. In addition, this enzyme also functions as a redox factor facilitating the DNAbinding of numerous transcription factors $[9,18,21]$. The removal of AP sites by specific enzymes can generate DNA strand breaks, which activate PARP-1. It is a conserved enzyme that catalyzes the polyADP- ribosylation of numerous nuclear proteins including histones, thereby playing an important role in BER and maintenance of genomic integrity $[19,22,23]$.

Recently, host genetic susceptibility to cancer related to polymorphisms in DNA enzymes repair have been investigated [24,25]. In GC some important polymorphisms to be investigated are: OGG-1 Ser326Cys (40676 A $\rightarrow \mathrm{G}$ ) in codon 326 of exon 7 [26,27], which has been associated with reduced DNA repair capacity [28]; APE-1 Asn148Glu $(2197 \mathrm{~T} \rightarrow \mathrm{G})$ in codon 148 of exon 5 [29,30], which has been reported to have an increased sensitivity to ionizing radiation in homozygosity [18,30]; and PARP-1 Val762Ala (40676 $\mathrm{A} \rightarrow \mathrm{G}$ ), in codon 762 of exon 17 , which has been associated with GC risk besides cag (+) H. pylori infection [23].

Considering all these points, it is important to investigate in GC patients, the interaction between the virulence of the infecting strain and the polymorphisms of host repair genes. Therefore, this study aimed to find an association between the $H$. pylori genotype and the above-mentioned polymorphisms, to elucidate the association between bacterial virulence factors and host genotype which favors GC development.

\section{RESULTS}

Among the 109 tumor samples analyzed, $H$. pylori was present in $92.6 \%(101 / 109)$ of the cases. Most cases involved male patients $(69 \%)$ and $53.2 \%$ were over 65 years old. Noncardiac accounted for $75.2 \%$ of the cases. The intestinal subtype was slightly more frequent than the diffuse subtype (55\% vs. $45 \%$, respectively). The patients in the intestinal subtype were significantly older $(\geq 65$ years old; $r=+0.261 ; P=0.006)$, whereas those of the diffuse subtype were younger ( $<45$ years old; $r=+0,265 ; P=0,005)$. A higher frequency of the cases $(61.5 \%)$ was classified as advanced grade (III-IV).

The genotype distributions for DNA repair enzymes of all samples are shown in the first line of Table I. A high frequency was found for the homozygous polymorphic $A P E-1$ (13.8\%; GG) genotype, contrasting with the low frequency found for the homozygous polymorphic genotypes of $O G G-1$ (4.6\%; GG) and PARP-1 $(3.7 \%$; GG). The genotype frequencies of these enzymes were not different according to the patient's age, using a cutoff of 50 years old. However, considering the histological subtypes, it was observed that in the intestinal subtype, $P A R P-1$ (AA) was statistically more frequent $(P=0.001)$ in patients $>50$ years old $[70 \%(39 / 55)]$. Considering the $>50$ years old group, the homozygous polymorphic PARP-1 genotype (GG) was characteristic of the diffuse subtype, differing statistically from the intestinal subtype $(P=0.002)$.

\section{Association of Repair Enzyme Genotypes and $H$. pylori Genes}

Taking into account the polymorphism of the repair enzymes and $H$. pylori genes, an association was observed between $H$. pylori cagE $(+)$ strains and the $P A R P-1$ and $A P E-1$ alleles. All homozygous polymorphic genotype carriers of $P A R P-1$ (GG) were infected by cag $\mathrm{E}(+)$ strains, while $70 \%$ patients infected by $\operatorname{cag\mathrm {E}}(-)$ strains were mainly wild-type (AA) carriers $(36 / 50, P=0.042)$. For $A P E-1$, the opposite was found; patients carrying the wild allele (TT $+\mathrm{TG})$ were positively correlated with $H$. pylori cagE $(+)$ strains $(r=+0.199 ; \quad P=0.046)$. Also, this group statically differed
$(P=0.049)$ from the patients carrying the homozygous variant (GG), where $73.3 \%$ (11/15) of the $A P E-1$ GG carriers were infected by $\operatorname{cagE}(-)$ strains. Additionally, patients carrying the $A P E-1$ wildtype genotype (TT) $(83.7 \%$; 31/37) were infected with vacAs $1 \mathrm{~m} 1$ strains, differing from the patients carrying the variant allele (TG $+\mathrm{GG} ; P=0.021$ ) or the homozygous polymorphic genotype (GG; $P=0.049$ ). Corroborating these data, patients carrying the polymorphic allele (TG $+\mathrm{GG}$ ) or the homozygous polymorphic genotype (GG) were statistically more infected with vacA $s 1 m 2 / s 2 m 1$ strains than patients with the wild-type (TT) genotype $(P=0.024$; $P=0.005$, respectively).

Considering the histological subtypes, in the intestinal tumors, $70 \%(12 / 17)$ of patients carrying the allele variant PARP-1 (AG/GG) were positively correlated with $H$. pylori cag $\mathrm{E}(+)$ strains $(r=$ $+0.272 ; P=0.043$ ), and also differed statistically from the patients carrying the wild-type genotype (AA; $P=0.041$ ). Moreover, in this histological subtype, 66\% (33/50) of patients carrying the $A P E-1$ wild allele $(\mathrm{TT}+\mathrm{TG})$ were infected by $H$. pylori virB $11(+)$ strains $(P=0.029)$. No associations were observed between $O G G-1$ genotypes and $H$. pylori genes. No associations were observed with the polymorphisms studied in the diffuse subtype.

\section{Analysis of $\boldsymbol{H}$. pylori Genotypes in Association With the Repair Enzyme Polymorphisms}

For these analysis, the cases were grouped according to $H$. pylori genotypes, using as division criteria the vacA alleles ( $s 1 \mathrm{~m} 1, s 1 \mathrm{~m} 2 /$ $s 2 m 1, s 2 m 2$ ) and the presence of cag pathogenicity island (cag-PAI) genes $(\operatorname{cag} \mathrm{A}, \operatorname{cag\mathrm {E}}$, and $\operatorname{vir} \mathrm{B} 11)$. Within this context, $\operatorname{cag} \mathrm{A}$ and $c a g \mathrm{E}$ were considered as right-side markers of the island, and vir B11 the left-side marker, as specified in Table I. Based on that, 12 groups were formed, and the A1 was considered the most virulent group while the $\mathrm{C} 4$ was considered the lower virulence group, as previously described in Lima et al. [12]. Thus, the high- or moderate-virulence strains were in $\mathrm{A} 1 \rightarrow \mathrm{B} 2$ groups and the low-virulence strains in $\mathrm{B} 3 \rightarrow \mathrm{C} 4$ groups.

In these analyses, all patients with homozygous polymorphic PARP-1 genotype (GG) were infected with strains from the A1 group, showing a statistically significant difference when compared with the other strain groups $(P=0.004)$. Also, in the intestinal subtype, a positive correlation was found (8/8: $r=+0.270 ; P=0.045)$ between the eight cases of $H$. pylori strain group without cag-PAI $(\mathrm{A} 4+\mathrm{B} 4+\mathrm{C} 4)$ and patients carrying PARP-1 wild-type (AA) genotype. All eight patients were $>50$ years old.

Concerning the $A P E-1$ polymorphism, it was observed that patients carrying the homozygous polymorphic $A P E-1$ genotype (GG) were infected with group B $(40 \%, 6 / 15)$ while patients carrying the wild-type genotype (TT) were infected with strain from group A1 $(35.1 \%, 13 / 37)$ with a statistically significant difference between them $(P=0.016)$. Genotype analysis of $O G G-1$ showed that homozygous variant (GG) was mainly infected by A2 strains, differing statically from the others $H$. pylori groups $(P=0.008)$.

Considering the most virulent and frequent group, A1, a positive correlation was found between the heterozygous (TG) of $A P E-1$ and wild-type (CC) of $O G G-1(r=+0.350 ; P=0.043)$. Correlations in the other groups were not examined due to the small number of cases.

Categorizing the $H$. pylori cases as high- or moderate-virulence strains $(\mathrm{A} 1 \rightarrow \mathrm{B} 2)$ and low-virulence strains $(\mathrm{B} 3 \rightarrow \mathrm{C} 4)$, it was observed that a significant frequency of patients carrying $P A R P-1$ polymorphic allele (AG or GG) was infected by high-virulence strains $(\mathrm{A} 1 \rightarrow \mathrm{B} 2)$ and that, curiously, the patients carrying PARP-1 wildtype genotype (AA) was significantly $(P=0.0396)$ infected by lowvirulence $(\mathrm{B} 3 \rightarrow \mathrm{C} 4) \mathrm{H}$. pylori strain (Fig. 1A). It is noteworthy that 14 of $19(73.6 \%)$ patients carrying the wild-type PARP-1 (AA) 


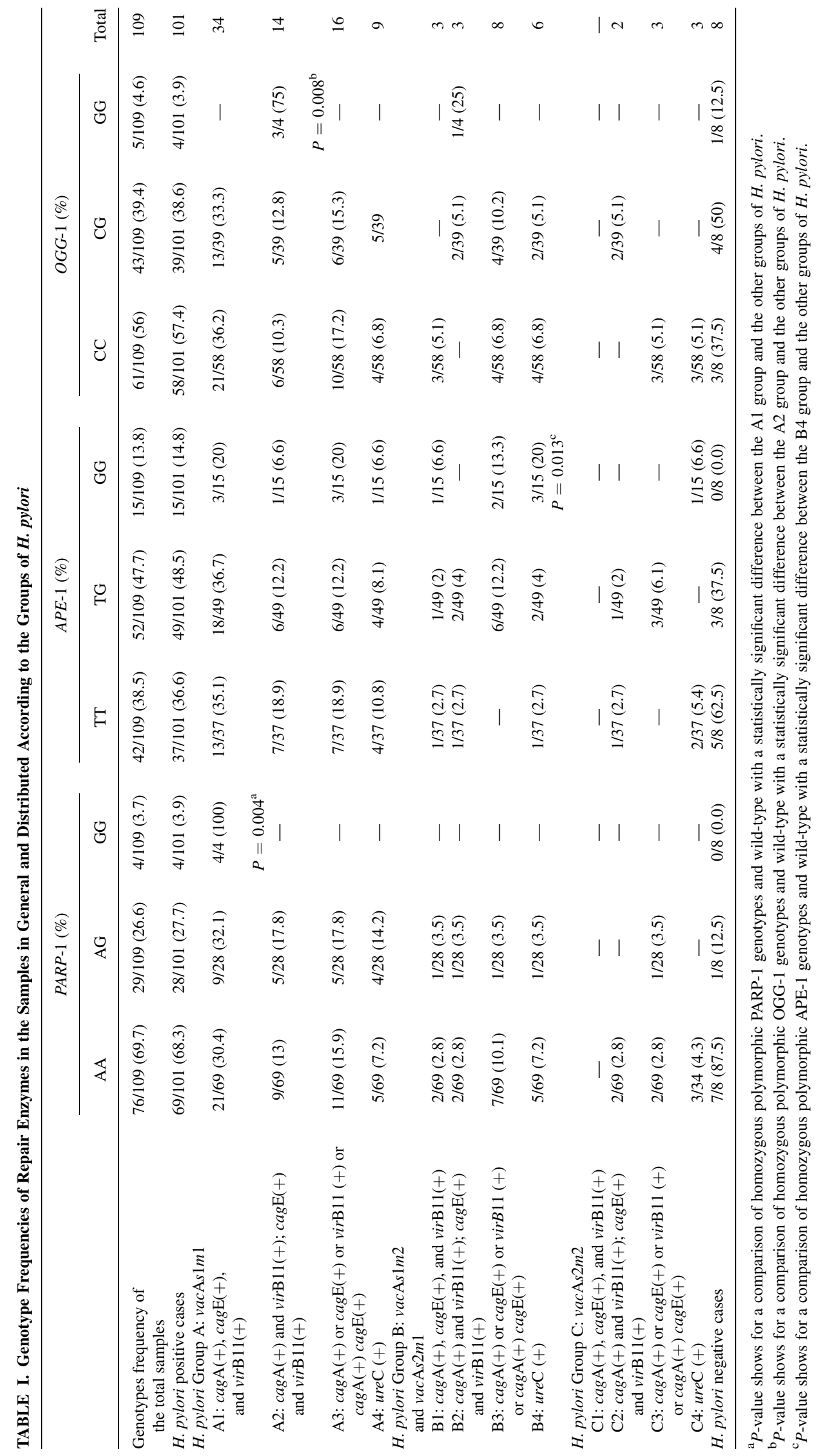


A

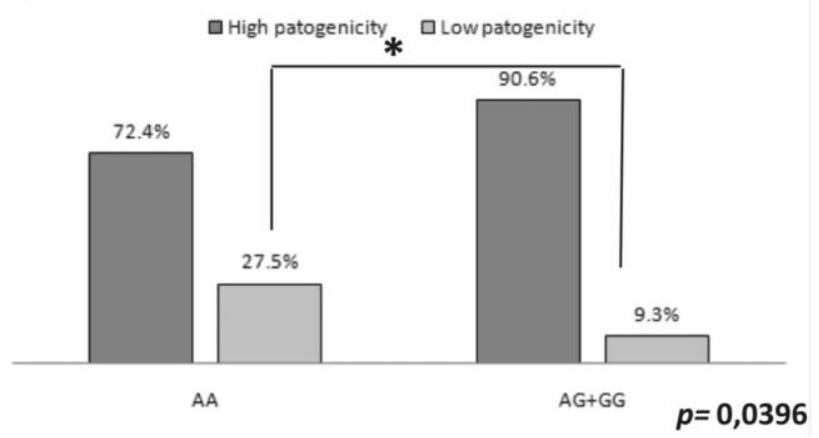

C

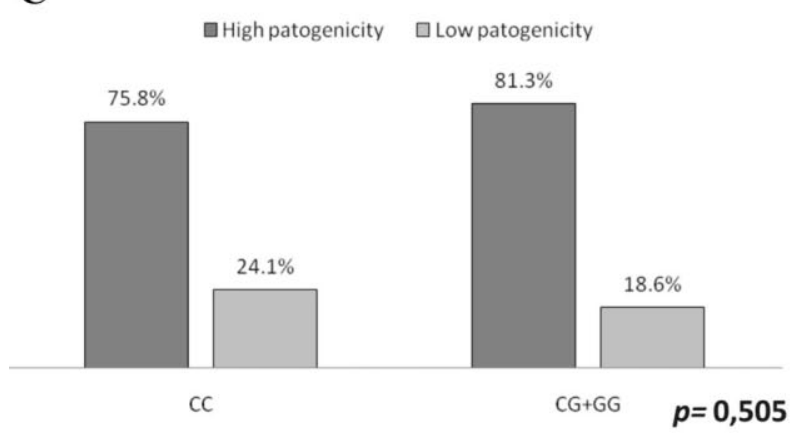

B

H. pylori strains and APE-1

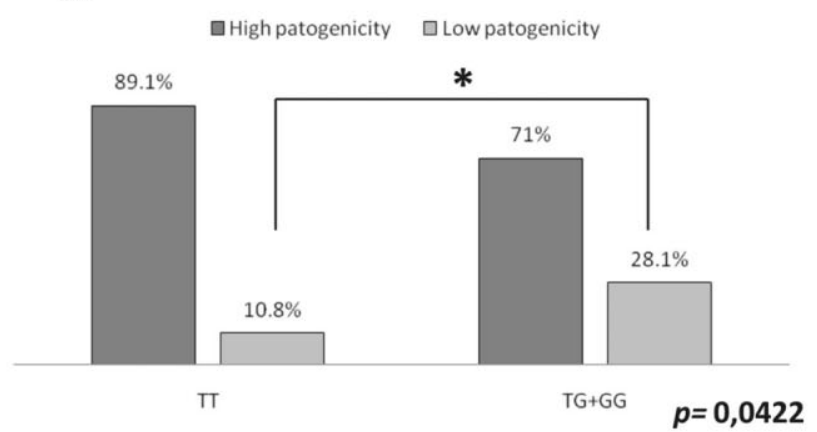

D H. pylori strains and wild-type genotypes

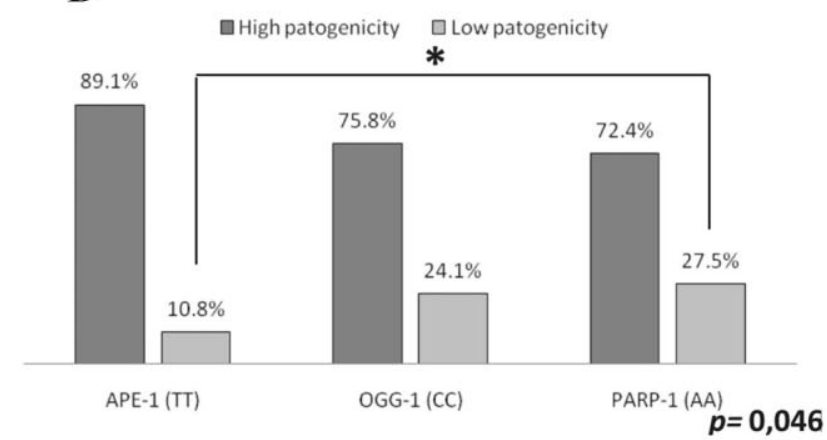

Fig. 1. Distribution of gastric cancer cases considering the infecting $H$. pylori pathogenicity strains in (A) $P A R P-1$ (B) $A P E-1,(\mathbf{C}) O G G-1$ genotypes, and (D) in wild-type of each studied enzyme repair. ${ }^{*} P<0.05$.

genotype and infected with low-virulence $(\mathrm{B} 3>\mathrm{C} 4)$ strains were $>55$ years old (Fig. 2), while four of five cases of PARP-1 (AA) and $<55$ years old infected with low-virulence strains were associated with the polymorphic allele of $A P E-1$ (TG or GG). Additionally, patients carrying the $A P E-1$ polymorphic allele (TG or GG) were infected by low-virulence strains $(P=0.0422)$, and patients carrying the wild-type genotype (TT) were mostly infected by high-virulence strains (Fig. 1B). Considering the $O G G-1$ genotypes (Fig. 1C), no difference was observed between the virulence of the infecting strain with $\mathrm{CC}$ versus $\mathrm{CG}+\mathrm{GG}(P=0.505)$, or between $\mathrm{CC}+\mathrm{CG}$ versus GG $(P=0.22)$ or $\mathrm{CC}$ versus CG $(P=0.67)$.

Comparison between the wild-type genotypes of repair enzymes according to $H$. pylori virulence is shown in Figure 1D. From this figure it is possible to observe that the low-virulence strains were statistically $(P=0.046)$ less frequent in patients carrying the wildtype (TT) of APE-1 than carrying the wild-type (AA) of PARP-1. These data confirm the previous data in which an association was observed between wild-type $P A R P-1$ genotype and less pathogenic H. pylori strains. No difference was found between $A P E-1$ and $O G G-1$ or between $O G G-1$ and $P A R P-1$ genotypes.

To observe the relevance of each polymorphism in the genes of repair enzymes, an analysis of associations between them was performed. Table II shows the frequencies of the genotype combination, considering two enzymes distributed according to the more and less virulent strains. This table also shows a significant association of the small number of cases infected with low-virulence strains in patients carrying the $A P E-1$ wild-type (TT) genotype when compared to those carrying the $A P E-1$ polymorphic allele, independent of the $O G G-1$ or $P A R P-1$ genotypes. When the $O G G-1$ and $P A R P-1$ were combined, the opposite was found; the less virulent strains were significantly more frequent $(86.3 \% ; 19 / 22)$ than patients carrying the $P A R P-1$ wild-type genotype (AA) regardless of the $O G G-1$ genotype.

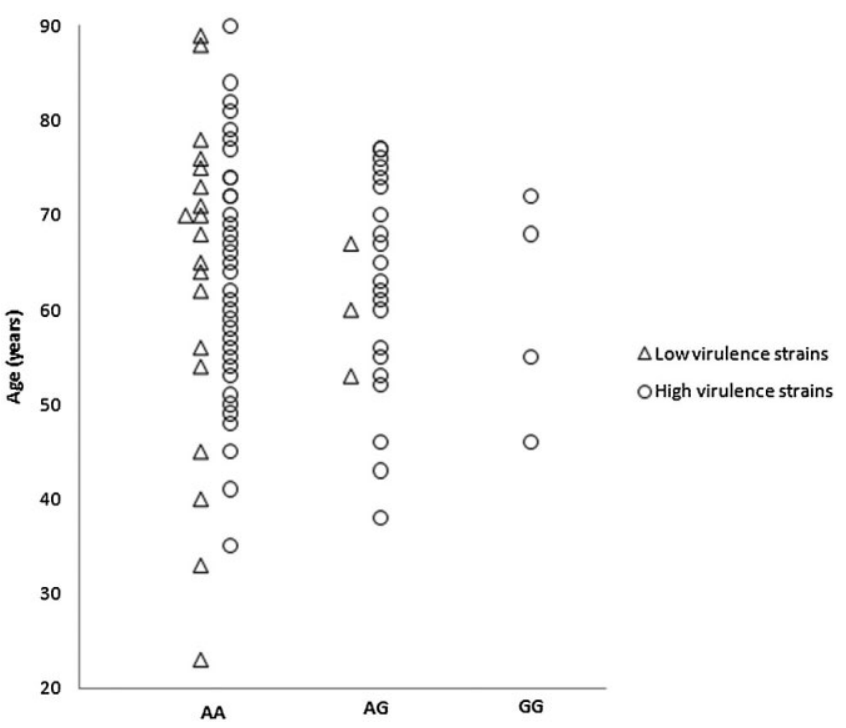

Fig. 2. Dispersion of gastric cancer cases classified as high $(\mathrm{A} 1 \rightarrow \mathrm{B} 2)$ and low $(\mathrm{B} 3 \rightarrow \mathrm{C} 4)$ virulent strains, distributed according to patients' age and $P A R P-1$ genotypes. The large number of $P A R P$-1 wild-type (AA) cases infected by low-virulence strains is associated with the advanced age of patients ( $>50$ years old). 
TABLE II. Frequency of Association of the Genes of Repair Enzymes Considering Two Enzymes and Comparing With the Strains More and Less Virulent

\begin{tabular}{|c|c|c|c|c|c|c|c|}
\hline $\operatorname{APE}(\mathrm{T} \rightarrow \mathrm{G})+$ OGG-1 $(\mathrm{C} \rightarrow \mathrm{G})$ & $\mathrm{A} 1 \rightarrow \mathrm{B} 2$ & $\mathrm{~B} 3 \rightarrow \mathrm{C} 4$ & $P$-Value & APE $(\mathrm{T} \rightarrow \mathrm{G})+$ PARP-1 $(\mathrm{A} \rightarrow \mathrm{G})$ & $\mathrm{A} 1 \rightarrow \mathrm{B} 2$ & $\mathrm{~B} 3 \rightarrow \mathrm{C} 4$ & $P$-Value \\
\hline $\mathrm{TT} / \mathrm{CC}$ & 18 & 3 & \multirow[t]{10}{*}{0.042} & TT/AA & 21 & 4 & \multirow[t]{10}{*}{0.042} \\
\hline TT/CG & 14 & 1 & & TT/AG & 10 & 0 & \\
\hline TT/GG & 1 & 0 & & \multirow[t]{2}{*}{ TT/GG } & 2 & 0 & \\
\hline (total) & (33) & (4) & & & (33) & (4) & \\
\hline TG/CC & 20 & 8 & & TG/AA & 23 & 9 & \\
\hline TG/CG & 14 & 4 & & TG/AG & 12 & 3 & \\
\hline TG/GG & 3 & 0 & & TG/GG & 2 & 0 & \\
\hline GG/CG & 3 & 3 & & GG/AA & 6 & 6 & \\
\hline $\mathrm{GG} / \mathrm{CC}$ & 6 & 3 & & GG/AG & 3 & 0 & \\
\hline (total) & $(46)$ & (18) & & & (46) & (18) & \\
\hline $\operatorname{PARP}(\mathrm{A} \rightarrow \mathrm{G})+\mathrm{OGG}(\mathrm{C} \rightarrow \mathrm{G})$ & & & \multirow[t]{11}{*}{0.0396} & \multicolumn{3}{|c|}{ PARP-1 $(\mathrm{A} \rightarrow \mathrm{G})+\operatorname{APE}(\mathrm{T} \rightarrow \mathrm{G})$} & \multirow[t]{11}{*}{0.0396} \\
\hline $\mathrm{AA} / \mathrm{CC}$ & 29 & 12 & & $\mathrm{AA} / \mathrm{TT}$ & 21 & 4 & \\
\hline $\mathrm{AA} / \mathrm{CG}$ & 18 & 7 & & & 23 & 9 & \\
\hline AA/GG & 3 & 0 & & \multirow[t]{2}{*}{ AA/GG } & 6 & 6 & \\
\hline (total) & $(50)$ & (19) & & & $(50)$ & (19) & \\
\hline $\mathrm{AG} / \mathrm{CC}$ & 13 & 2 & & AG/TT & 10 & 0 & \\
\hline $\mathrm{AG} / \mathrm{CG}$ & 11 & 1 & & AG/TG & 12 & 3 & \\
\hline AG/GG & 1 & 0 & & AG/GG & 3 & 0 & \\
\hline $\mathrm{GG} / \mathrm{CC}$ & 2 & 0 & & GG/TT & 2 & 0 & \\
\hline GG/CG & 2 & 0 & & GG/TG & 2 & 0 & \\
\hline (total) & $(29)$ & (3) & & & (29) & (3) & \\
\hline $\mathrm{OGG}(\mathrm{C} \rightarrow \mathrm{G})+\operatorname{APE}(\mathrm{T} \rightarrow \mathrm{G})$ & & & \multirow[t]{11}{*}{0.505} & \multicolumn{3}{|c|}{ OGG $(\mathrm{C} \rightarrow \mathrm{G})+$ PARP-1 $(\mathrm{A} \rightarrow \mathrm{G})$} & \multirow[t]{11}{*}{0.505} \\
\hline $\mathrm{CC} / \mathrm{TT}$ & 18 & 3 & & CC/AA & 29 & 12 & \\
\hline $\mathrm{CC} / \mathrm{TG}$ & 20 & 8 & & $\mathrm{CC} / \mathrm{AG}$ & 13 & 2 & \\
\hline $\mathrm{CC} / \mathrm{GG}$ & 6 & 3 & & $\mathrm{CC} / \mathrm{GG}$ & 2 & 0 & \\
\hline (total) & (44) & (14) & & & (44) & (14) & \\
\hline CG/TT & 14 & 1 & & CG/AA & 18 & 7 & \\
\hline CG/TG & 14 & 4 & & CG/AG & 11 & 1 & \\
\hline CG/GG & 3 & 3 & & CG/GG & 2 & 0 & \\
\hline GG/TT & 1 & 0 & & GG/AA & 3 & 0 & \\
\hline GG/TG & 3 & 0 & & GG/AG & 1 & 0 & \\
\hline (total) & (35) & (8) & & & (35) & (8) & \\
\hline
\end{tabular}

However, the combination of three genotypes (Table III) shows that these patients carrying the $P A R P-1$ wild-type (AA) genotype and infected by low-virulence strains were commonly associated with the polymorphic allele of APE-1 $(78.94 \% ; 15 / 19)$. Moreover, the number of cases of triple wild-type genotype infected by low-virulence strains (B3 $\rightarrow \mathrm{C} 4)$ was very low (only three).

\section{DISCUSSION}

Polymorphisms in several DNA repair enzymes, including genes of $A P E-1, O G G-1$, and $P A R P-1$ have been studied in various cancers, including GC, due of its critical role in maintaining genome integrity [24,26,31]. Some experimental and case-control studies have shown that functional variations in these genes can alter the functions of the BER system [23,29,32-35]. Unlike these reports, the present study aimed to investigate the polymorphisms in repair enzymes considering the histopathology of GC and, for the first time, the in vivo association between the genotype of the strain of $H$. pylori and genepolymorphisms of DNA repair enzymes $A P E-1, O G G-1$, and PARP-1.

In the population studied, the polymorphic allele of $A P E-1$ (T2197G) which is described as a common allele in the world population, was found in a high frequency [29], been the heterozygous genotype the most frequent, as in others studies [30,32,35]. The low frequency $(4 \%)$ of the homozygous polymorphic $O G G-1$ genotype (GG) was similar to that reported by Li et al. [30] in Texan patients with cutaneous melanoma (3\%) and by Hanaoka et al. [36] in Brazilian GC patients (4\%), but it differed from Brazilians of Japanese descent (16\%), showing an ethnic background influence. The homozygous polymorphic genotype frequency of $P A R P-1$ (GG) varies widely according to the population studied, ranging from $2 \%$ to $19.9 \%$ in studies from United States [37] and from China [38], respectively, indicating possible ethnic differences for the presence of this polymorphic allele.

Considering these genotypes and the characteristic of the patients and the histopathology of the studied GC tumors, it was observed that, although no difference has been found between genotype distribution and the histological subtypes, a statistically significant difference was shown between intestinal and diffuse subtypes when age was considered. Analyzing the $>50$ years old patients group, $70 \%$ patients carrying the $P A R P-1$ wild-type (AA) was significantly associated with the intestinal subtype, which was significantly composed of older patients ( $\geq 65$ years), and conversely, patients carrying the homozygous variant (GG) was associated with the diffuse type, composed of the younger patients and the more aggressive subtype. This association could been explained when the PARP-1 activity is taking in account. It is interesting to note that in cell culture experiment Mishra and Das [39] and Quesada et al. [40] demonstrated a reduction of the natural activity of PARP-1 related to age. These findings could explain the high frequency of the wild-type of PARP1 (AA) found in this study since our sample comprised mainly older patients, and the vulnerability to DNA damages in old age suggested by Strosznajder et al. [41] using animal models. However, additional studies are required to confirm, in vivo, the low enzyme activity associated with age progression.

In gastric carcinogenesis, the relationship between the bacteria and the host is not completely understood. Here, we hypothesized a relationship between the bacterial genotype and the polymorphism of repair enzyme genes involved in oxidative stress. Thus, the polymorphism was considered taking into account single bacterial genes and 
TABLE III. Analysis of the Three Enzyme Repair Genotypes Associated, Keeping the Wild-Type Genotype of Each One Fixed at a Time

\begin{tabular}{|c|c|c|}
\hline $\begin{array}{l}\text { APE }(\mathrm{T} \rightarrow \mathrm{G}) \text {; OGG }(\mathrm{C} \rightarrow \mathrm{G}) \\
\operatorname{PARP}(\mathrm{A} \rightarrow \mathrm{G})\end{array}$ & $\mathrm{A} 1 \rightarrow \mathrm{B} 2$ & $\mathrm{~B} 3 \rightarrow \mathrm{C} 4$ \\
\hline \multicolumn{3}{|l|}{ Wild-type (WT) } \\
\hline TT/CC/AA (WT) & 14 & 3 \\
\hline \multicolumn{3}{|l|}{ APE-1 (WT) fixed } \\
\hline TT/CG/AA & 6 & 1 \\
\hline TT/CC/AG & 4 & 0 \\
\hline TT/CG/AG & 6 & 0 \\
\hline TT/GG/AA & 1 & 0 \\
\hline TT/CC/GG & 0 & 0 \\
\hline TT/CG/GG & 2 & 0 \\
\hline TT/GG/AG & 0 & 0 \\
\hline Subtotal & 19 & 1 \\
\hline Total $^{\mathrm{a}}$ & 33 & 4 \\
\hline \multicolumn{3}{|l|}{ OGG-1 (WT) fixed } \\
\hline TG/CC/AA & 12 & 6 \\
\hline TT/CC/AG & 4 & 0 \\
\hline TG/CC/AG & 6 & 2 \\
\hline GG/CC/AA & 3 & 3 \\
\hline TT/CC/GG & 0 & 0 \\
\hline GG/CC/AG & 3 & 0 \\
\hline $\mathrm{TG} / \mathrm{CC} / \mathrm{GG}$ & 2 & 0 \\
\hline Subtotal & 30 & 11 \\
\hline Total $^{\mathrm{a}}$ & 44 & 14 \\
\hline \multicolumn{3}{|l|}{ PARP-1 (WT) fixed } \\
\hline TT/CG/AA & 6 & 1 \\
\hline TG/CC/AA & 12 & 6 \\
\hline TG/CG/AA & 9 & 3 \\
\hline TT/GG/AA & 1 & 0 \\
\hline GG/CC/AA & 3 & 3 \\
\hline TG/GG/AA & 2 & 0 \\
\hline GG/CG/AA & 3 & 3 \\
\hline Subtotal & 36 & 16 \\
\hline Total $^{\mathrm{a}}$ & 50 & 19 \\
\hline
\end{tabular}

${ }^{\mathrm{a}}$ The total considers the triple wild-type along with the polymorphic associations.

genotypes beyond the histological GC subtypes. Considering the frequency of polymorphisms in association with the single $H$. pylori genes, it was observed that among the bacterial genes, cagE stood out, since the presence of this bacterial gene was significantly correlated with heterozygotes genotype of PARP-1 (GG) carriers in the intestinal subtype and in the total sample, with the wild allele of $A P E-1$ (TT + TG). These data indicate the importance of $c a g \mathrm{E}$ in gastric carcinogenesis, explaining the high frequency of this bacterial gene found in GC described in previous studies from our research group [12]. Additionally, Tiwari et al. [42] showed that cagE has a high predictive value for the development of GC along with other genes of the bacterium, such as $\operatorname{cag} \mathrm{T}, \operatorname{hrg} \mathrm{A}, \operatorname{cag} \mathrm{A}$, and $v a c \mathrm{~A} s 1 m 1$.

To understand the influence of $H$. pylori genotype infection associated with host $A P E-1, O G G-1$, and $P A R P-1$ genotypes, $H$. pylori genotypes were grouped as suggested by Lima et al. [12]. The presence of strains in group A1 associated with the wild-type carriers of all three repair enzymes genes point to the relevance of strain virulence in gastric carcinogenesis. Overall, the association between strains from virulent groups A1, A2 with patients with homozygous polymorphic genotype of $P A R P-1$ (GG) and $O G G-1(\mathrm{GG})$, respectively, and strain from B4 (a group considered not a virulent group) with patients with homozygous polymorphic genotype for $A P E-1$ (GG) showed the relevance of host susceptibility conferred by polymorphic allele associated with certain strains (virulent or moderate strains of $H$. pylori).

As the A1 group was the more frequent group and consisted of the more virulent strains, the data from this group were analyzed separately. In this analysis, a significant correlation between the heterozygous of $A P E-1$ (TG) and wild-type of $O G G-1$ (CC) was found, highlighting the importance of the polymorphic allele of $A P E-1$. These data are also corroborated by the significant association between the variant allele of $A P E-1$ (GG) and strains with moderate virulence, $v a c \mathrm{~A} s 1 m 2 / s 2 m 1$. It is known that in BER, $A P E-1$ interacts with $O G G-1$, so that the reduced ability of the polymorphic enzyme APE-1 in interacting with OGG-1, besides other proteins in BER, results in decreased efficiency of this pathway and disease susceptibility as hypothesized by Hadi et al. [29], placing the significance of $O G G$-1 wild-type in a secondary position, in this case, in relation to the $A P E-1$ variant. The interaction of these two enzymes has also been observed by Vodicka et al. [32] which showed a significant decrease in DNA damage repair capacity associated with the same variant allele of $O G G-1$ and $A P E-1$ analyzed in this study. These same polymorphisms were also associated with increased risk of colorectal cancer in individuals simultaneously homozygous for the variant alleles [34].

On the other hand, considering only the less virulent strains (A4 + B4 + C4), it was found, in the intestinal subtype, that patients with wild-type genotype (AA) of $P A R P-1$ were significantly associated with these strains. The cellular susceptibility to infection by strains described as low virulence by wild PARP-1 could possibly be due to the low enzyme activity associated with the age progression mentioned before, since 8/8 patients from A4 + B4 + C4 group were $>50$ years old. Another possibility involves the metabolic aspects of PARP-1. It is known that the activity of PARP-1, polymerizing ADP-ribose and transferring it to various nuclear proteins, consumes NAD + and thus consumes cellular energy. Although PARP-1 has an important role in the cellular repair, its activation can cause necrosis and inflammation due to the depletion energy [43], contributing to the carcinogenic process.

As it was found, same apparently unexpected results (association of low virulence strains with wild-types genotypes of the repair enzymes), the host genotype for repair enzymes were combined two by two and compared with the bacterial high $(\mathrm{A} 1 \rightarrow \mathrm{B} 2)$ or low $(\mathrm{B} 3 \rightarrow \mathrm{C} 4)$ strains. The polymorphisms in enzymes $A P E-1$ and $P A R P-1$ stood out. APE-1 polymorphic allele showed a strong susceptibility to infection by less pathogenic strains, regardless of the genotypes of $P A R P-1$ or $O G G-1$, corroborating the experimental findings from Hadi et al. [29] and Vodicka et al. [32] related to inability of the variant enzyme of $A P E-1$ to interact with other BER repair enzymes. PARP-1 wild-type genotype (AA), in turn, showed a strong association with less pathogenic strains $(B 3 \rightarrow C 4)$ infection. However, the majority, $73.6 \%(14 / 19)$ of the patients, carrying the $P A R P$-1 wild-type (AA) genotype and infected with low-virulence (B3 $>$ C4) strains were $>55$ years old (as seen in Fig. 2), while the five cases of PARP-1 (AA) and $<55$ years old infected with lowvirulence strains were associated with the polymorphic allele of $A P E-1$ (TG or GG), suggesting that patients carrying the wild genotype of $P A R P-1$ (AA) and infected with low virulence strains are more susceptive to cancer development when they also carries the polymorphic allele of $A P E-1$ or are in advanced age.

To better understand the reason why the genotypes coding for efficient enzymes (wild-type genotypes) were infected with lowvirulence strains (see Fig. 1D), a qualitative analysis was performed fixing the wild-type of one of the enzymes and combining with the others. It was thereby possible to observe that just a small frequency of cases with triple wild-type genotype carrier was infected by low-virulence strains. The virulent strains associated with this genotype show the importance of the $H$. pylori genotype, which was related to GC even in the presence of an efficient repair system. For patients carrying the PARP-1 wild-type (AA) genotype, it was confirmed that they were commonly associated with the polymorphic allele of $A P E-1(78.94 \% ; 15 / 19)$. Also these analyses showed that 
$A P E$-1 wild-type (TT) was associated with the lower number of cases infected by more virulent strains $(\mathrm{A} 1 \rightarrow \mathrm{B} 2)$ compared with the others.

Thus, the finding of this study showed that the associations between low/moderate virulence strains with the presence of polymorphic allele of $A P E-1$ highlights the relevance of this polymorphic enzyme in gastric carcinogenesis with low-virulence strains. On the other hand, the wild-type of $P A R P-1$ (AA) seems to be less effective against the same $H$. pylori strains in older subjects, whereas in young patients with this PARP-1 genotype, the lowvirulence strains contributes to the gastric carcinogenesis in the simultaneous presence of the polymorphic allele of $A P E-1$. Concerning $O G G-1$, no substantial results were found with this analysis, despite the large number of studies showing its importance as a repair enzyme, suggesting that the role of $O G G-1$ is secondary to that of $A P E-1$ and $P A R P-1$. This is possibly due to the fact that the AP site generated by OGG-1 activity, if not corrected by a functional APE-1, may result in further damage, and carcinogenesis process.

Moreover, in this study, the importance of the $H$. pylori genotype was highlighted, since patients with the wild-type for the three repair enzymes studied were significantly infected by high-virulence strains. Taken together, our data lead to an important clue in understanding the role of low-virulence strains of $H$. pylori in gastric carcinogenesis. Also emphasize the need to analyze host polymorphisms considering their combination as well as the $H$. pylori genotype (unlike its single genes).

\section{MATERIALS AND METHODS}

\section{Study Population}

The present work was approved by the ethics committee of the Federal University of Ceará under protocol no. 047.06.09. All subjects signed an informed consent form before inclusion. A total of 109 gastric tumor samples, surgically resected, were obtained from two hospitals in the state of Ceará, Brazil: Walter Cantideo Hospital at the Federal University of Ceará and Santa Casa de Misericórdia Hospital, both located in Fortaleza, the state capital. The tumor fragments were collected during gastrectomies, and the specimens were then subjected to DNA extraction. The histological diagnosis and tumor classification were based on Lauren's criteria. No patients had received chemotherapy or radiation therapy before surgery.

\section{DNA Extraction}

Genomic DNA was extracted from frozen tumor tissue samples, using the cetyltrimethyl ammonium bromide (CTAB) method adapted from Foster and Twell [44], only when the histopathological analysis determined that the tumor specimens consisted mainly $(>80 \%)$ of tumor cells. DNA quality was analyzed by $1 \%$ agarose gel electrophoresis with ethidium bromide staining. DNA concentration and $\mathrm{A}_{260} / \mathrm{A}_{280}$ ratio were determined using a Thermo Scientific NanoDrop ${ }^{\mathrm{TM}} 3300$ fluorospectrometer (Wilmington, DE).

\section{Genotyping $\boldsymbol{H}$. pylori}

The resected tissues were used to detect $H$. pylori infection and their respective genes by polymerase chain reaction (PCR). H. pylori detection was performed by amplification of the urease $\mathrm{C}$ gene. PCR mixtures were prepared in a final volume of $25 \mu$ l containing $1.5 \mathrm{mM} \mathrm{MgCl} 2,0.2 \mathrm{mM}$ dNTPs, $0.4 \mu \mathrm{M}$ each primer set, $1.25 \mathrm{U}$ Platinum Taq DNA polymerase (Invitrogen, São Paulo, SP, Brazil), and $100 \mathrm{ng}$ DNA. The reaction conditions were previously described [45]. Negative (water) and positive (DNA containing known H. pylo$r i$ positive genes) controls were assayed in each run. PCR products were separated on $6 \%$ nondenaturing polyacrylamide electrophoretic gels stained with silver.

\section{DNA Repair Polymorphism}

Single nucleotide polymorphisms (SNPs) for DNA repair genes were determined by a PCR-(restriction fragment length polymorphism-RFLP) based method. For $A P E-1$ and $O G G-1$, PCR products were generated using, in each reaction, a total volume of $25 \mu \mathrm{l}$ containing $10 \mathrm{pM}$ each primer, 3.6 U Platinum Taq DNA polymerase (Invitrogen ${ }^{\mathrm{R}}$ ), $0.3 \mathrm{mM}$ dNTPs, $2.0 \mathrm{mM} \mathrm{MgCl} 2$, and $100 \mathrm{ng}$ DNA template. To amplify the $P A R P-1$ gene, the PCR products were generated in a final volume of $20 \mu \mathrm{l}$ containing PCR MasterMix $1 \times$ (Promega, Madison, WI), $0.4 \mu \mathrm{M}$ each primer, and $100 \mathrm{ng}$ DNA template.

The reactions proceeded under the following conditions: initial denaturation at $94^{\circ} \mathrm{C}$ for $4 \mathrm{~min}$, followed by 35 cycles of $94^{\circ} \mathrm{C}$ $45 \mathrm{sec}$, annealing temperature as described in Table IV, and extension at $72^{\circ} \mathrm{C}$ for $1 \mathrm{~min}$. An extension period for $5 \mathrm{~min}$ followed the final cycle. Negative (water) and positive (DNA containing known each DNA repair genes) controls were assayed in each run. The amplified fragments were visualized in $2 \%$ agarose gels containing ethidium bromide under UV light and were digested with appropriate restriction endonucleases. The restriction enzymes and the fragment size are described in Table IV. The fragments were resolved by $8 \%$ nondenaturing polyacrylamide electrophoretic gels and silver staining. Randomly selected samples were re-genotyped (10\% of samples).

\section{Statistical Analysis}

The statistical analyses were conducted using the EPINFO ${ }^{\circledR} 6.0$ or SPSS ${ }^{\circledR} 15.0$ version statistical software program (SPSS, Chicago, IL). Statistically significant differences were evaluated by the chi-square test $\left(\chi^{2}\right)$ and Fisher's exact test. Correlations between expression of the proteins and histological subtype were analyzed using Spearman's correlation coefficient. A $P$-value less than 0.05 was regarded as statistically significant.

\section{ACKNOWLEDGMENTS}

We thank Ministério da Ciência e Tecnologia/Conselho Nacional de Desenvolvimento Científico e Tecnológico (MCT/CNPq) 480554/ 20080 and Coordenação de Aperfeiçoamento de Pessoal de Nível Superior (CAPES) for financial support.

TABLE IV. Details on Investigated SNPs in DNA Repair Genes

\begin{tabular}{|c|c|c|c|c|c|}
\hline Genetic polymorphism & Primer sequence & Annealing temp. $\left({ }^{\circ} \mathrm{C}\right)$ & Restriction enzyme & Fragments size & Reference \\
\hline APE-1 (Asn148Glu) & $\begin{array}{l}\text { F: 5'CTGTTTCATTTCTATAGGCTA3' } \\
\text { R: 5'AGGAACTTGCGAAAGGCTTC } 3^{\prime}\end{array}$ & 48.5 & $B f a \mathbf{I}$ & $\begin{array}{c}\text { T } 164 \\
\text { G } 144 \text { and } 20\end{array}$ & [32] \\
\hline OGG-1 (Ser326Cys) & $\begin{array}{l}\text { F: 5'AGTGGATTCTCATTGCCTTCG3' } \\
\text { R: } 5^{\prime} \text { GGTGCTTGGGGAATTTCTTT3' }\end{array}$ & 54 & Fnu4HI & $\begin{array}{c}\text { C } 250 \\
\text { G154 and } 96\end{array}$ & [32] \\
\hline PARP-1 (Val762Ala) & $\begin{array}{l}\text { F: } 5^{\prime} \text { TTTGCTCCTCCAGGCCAACG3' } \\
\text { R: } 5^{\prime} \text { ACATCGATGGGATCCTTGCTGC } 3^{\prime}\end{array}$ & 57.5 & $B s t \mathrm{UI}$ & $\begin{array}{c}\text { A } 127 \\
\text { G107 and } 20\end{array}$ & Drawn by authors ${ }^{\mathrm{a}}$ \\
\hline
\end{tabular}

\footnotetext{
${ }^{\mathrm{a}}$ The program Primer-Introduced Restriction Analysis (PIRA-PCR).
} 


\section{REFERENCES}

1. Wen S, Moss SF: Helicobacter pylori virulence factors in gastric carcinogenesis. Cancer Lett 2009;282:1-8.

2. Inca-Instituto Nacional do Câncer. Estimativas 2010: Incidência de câncer no Brasil, Rio de Janeiro; 2009

3. Werner M, Becker KF, Keller G, et al.: Gastric adenocarcinoma: Pathomorphology and molecular pathology. J Cancer Res Clin Oncol 2001;127:207-216.

4. Espejo E, Navarrete SJ: Classification of stomach adenocarcinomas. Rev Gastroenterol 2003;23:199-212.

5. Bork AMGT, Barone B: The two histological main types of gastric carcinoma: Diffuse and so-called intestinal-type carcinoma. Einstein: Educação Continuada em Saúde 2007;5:114-115.

6. Konturek PC, Konturek SJ, Brzozowski T: Gastric cancer and Helicobacter pylori infection. J Physiol Pharmacol 2006;57: $51-65$.

7. Crew KD, Neugut AI: Epidemiology of gastric cancer. World J Gastroenterol 2006;12:354-362.

8. Hartgrink HH, Jansen EPM, Van Grieken NCT, et al.: Gastric cancer. Lancet 2009;374:477-490.

9. Ding S, O'Hara AM, Denning TL, et al.: Helicobacter pylori and $\mathrm{H}_{2} \mathrm{O}_{2}$ increase AP endonuclease- 1 /redox factor- 1 in human gastric epithelial cells. Gastroenterology 2004;127:845-858.

10. Reyes-Leon A, Atherton JC, Argent RH, et al.: Heterogeneity in the activity of Mexican Helicobacter pylori strains in gastric epithelial cells and its association with diversity in the cagA gene. Infect Immun 2007;75:3445-3454.

11. Sugimoto M, Yamaoka Y: Virulence factor genotypes of Helicobacter pylori affect cure rates of eradication therapy. Arch Immunol Ther Exp 2009;57:45-56.

12. Lima VP, Lima MAP, Ferreira MVP, et al.: The relationship between Helicobacter pylori genes cagE and virB 11 and gastric cancer. Int J Infect Dis 2010;14:613-617.

13. Fukuta K, Azuma T, Ito Y, et al.: Clinical relevance of cagE gene from Helicobacter pylori strains in Japan. Digest Dis Sci 2002;47:667-674.

14. Backert S, Selbach M: Role of type IV secretion in Helicobacter pylori. Pathog Cell Microbiol 2008;10:1573-1581.

15. Nguyen LT, Uchida T, Murakami K, et al.: Helicobacter pylori virulence and the diversity of gastric cancer in Asia. J Med Microbiol 2008;57:1445-1453.

16. Costa MT, Fabeni RC, Aptekmann KP, et al.: Diferentes papéis do óxido nítrico com ênfase nas neoplasias. Ciência Rural 2003;33:967-974.

17. Ladeira MSP, Salvador DMF, Rodrigues MAM: Biopatologia do Helicobacter pylori. J Bras Patol Med Lab 2003;39:335-342.

18. $\mathrm{Lu} \mathrm{A}, \mathrm{Li} \mathrm{X}, \mathrm{Gu}$ Y, et al.: Repair of oxidative DNA damage (Review). Cell Biochem Biophys 2001;35:141-170.

19. Kauppinen TM: Multiple roles for poly (ADP-ribose)polymerase-1 in neurological disease. Neurochem Int 2007;50:954-958.

20. David SS, O'Shea VL, Kundu S: Base-excision repair of oxidative DNA damage. Nature 2007;447:941-950.

21. Hu JJ, Smith TR, Miller MS, et al.: Amino acid substitution variants of APE1 and XRCC1 genes associated with ionizing radiation sensitivity. Carcinogenesis 2001;22:917-922.

22. Gonzales-Rey E, Martínez-Romero R, Ovalle F, et al.: Therapeutic effect of poly(ADP-ribose) polymerase-1 inhibitor on experimental arthrits by downregulating inflammation and Th1 response. PLOS ONE 2007;10:1-6.

23. Zhang Q, Li Y, Li X, et al.: PARP-1 Val762Ala polymorphism, $\mathrm{CagA}+H$. pylori infection and risk for gastric cancer in Han Chinese population. Mol Biol Rep 2009;36:1461-1467.

24. Hung RJ, Hall J, Brennan P, et al.: genetic polymorphisms in the base excision repair pathway and cancer risk: A HuGE review. Am J Epidemiol 2005;162:925-942.

25. Bertram C, Hass R: Cellular responses to reactive oxygen species-induced DNA damage and aging. J Biol Chem 2008;389: 211-220.
26. Goode EL, Ulrich CM, Potter JD: Polymorphisms in DNA repair genes and associations with cancer risk. Cancer Epidemiol Biomarkers Prev 2002;11:1513-1530.

27. Sugimura H, Kohno T, Wakai K, et al.: hOGG1 Ser326Cys polymorphism and lung cancer susceptibility. Cancer Epidemiol Biomarkers Prev 1999;8:669-674.

28. Ruyck KD, Szaumkessel M, Rudder ID, et al.: Polymorphisms in base-excision repair and nucleotide-excision repair genes in relation to lung cancer risk. Mut Res Gen Toxicol Environ Mut 2007;631:101-110

29. Hadi MZ, Coleman MA, Fidelis K, et al.: Functional characterization of APE1 variants identified in the human population. Nucleic Acids Res 2000;28:3871-3879.

30. Li C, Liu Z, Wang L, et al.: Genetic variants of the ADPRT, XRCC1 and APE1 genes and risk of cutaneous melanoma. Carcinogenesis 2006;27:1894-1901.

31. Capellá G, Pera G, Sala N, et al.: DNA repair polymorphisms and the risk of stomach adenocarcinoma and severe chronic gastritis in the EPIC-EURGAST study. Int J Epidemiol 2008;37: 1316-1325.

32. Vodicka P, Stetina R, Polakova V, et al.: Association of DNA repair polymorphisms with DNA repair functional outcomes in healthy human subjects. Carcinogenesis 2007;28:657664.

33. Figueroa JD, Malats N, Real FX, et al.: Genetic variation in the base excision repair pathway and bladder cancer risk. Hum Genet 2007;121:233-242.

34. Pardini B, Naccarati A, Novotny J, et al.: DNA repair genetic polymorphisms and risk of colorectal cancer in the Czech Republic. Mutat Res 2008;638:146-153.

35. Li WQ, Zhang L, Ma JL, et al.: Association between genetic polymorphisms of DNA base excision repair genes and evolution of precancerous gastric lesions in a Chinese population. Carcinogenesis 2009;3:500-505.

36. Hanaoka T, Sugimura H, Nagura K, et al.: hOGG1 exon7 polymorphism and gastric cancer in case-control studies of Japanese Brazilians and non-Japanese Brazilians. Cancer Lett 2001;170: 53-61.

37. Wang SS, Davis S, Cerhan JR, et al.: Polymorphisms in oxidative stress genes and risk for non-Hodgkin lymphoma. Carcinogenesis 2006;27:1828-1834.

38. Zhai X, Liu J, Hu Z, et al.: Polymorphisms of ADPRT Val762Ala and XRCC1 Arg399Glu and risk of breast cancer in Chinese women: A case control analysis. Oncol Rep 2006;15 247-252.

39. Mishra SK, Das BR: (ADP-ribosyl)ation pattern of chromosomal proteins during ageing. Cell Mol Biol 1992;38:57-462.

40. Quesada P, Faraone-Mennella MR, Jones R, et al.: ADPribosylation of nuclear proteins in rat ventral prostate during ageing. Biochem Biophys Res Commun 1990;170:900907.

41. Strosznajder JB, Jeśko H, Strosznajder RP: Age-related alteration of poly(ADP-ribose) polymerase activity in different parts of the brain. Acta Biochim Pol 2000;47:331-337.

42. Tiwari SK, Manoj G, Kumar GV, et al.: Prognostic significance of genotyping Helicobacter pylori infection in patients in younger age groups with gastric cancer. Postgrad Med J 2008;84: 193-197.

43. Peddi SR, Chattopadhyay R, Naidu CV, et al.: The human apurinic/apyrimidinic endonuclease-1 suppresses activation of poly(adp-ribose) polymerase-1 induced by DNA single strand breaks. Toxicology 2006;224:44-55.

44. Foster GD, Tweel D, editors: Plant gene isolation. Principles and pratics. England: John Wiley \& Sons; 1996

45. Lima VP, Silva-Fernandes IJL, Alves MKS, et al.: Prevalence of Helicobacter pylori genotypes (vacA, cagA, cagE and virB11) in gastric cancer in Brazilian's patients: An association with histopathological parameters. Cancer Epidemiol 2011;35: e32-7. 